\title{
Emigration, Immigration, and Skill Formation: The Case of a Midstream Country
}

\author{
Kenji Kondoh \\ School of Economics, Chukyo University, 101-2 Yagotohonmachi, Showaku, Nagoya 4668666, Japan \\ Correspondence should be addressed to Kenji Kondoh; kkondo@mecl.chukyo-u.ac.jp
}

Received 7 January 2014; Revised 26 May 2014; Accepted 9 June 2014; Published 30 June 2014

Academic Editor: Alberto Davila

Copyright (C) 2014 Kenji Kondoh. This is an open access article distributed under the Creative Commons Attribution License, which permits unrestricted use, distribution, and reproduction in any medium, provided the original work is properly cited.

\begin{abstract}
This study theoretically investigates the economy of a small country that exports skilled labor to higher developed countries and simultaneously imports unskilled labor from lower developed countries. Compared with the free immigration case, if this country adopts an optimally controlled immigration policy by imposing income tax on immigrants to maximize national income, skills formation is negatively affected and the number of domestic unskilled workers increases. Moreover, under certain conditions, we can assert the counter-intuitive possibility that the wage rate of domestic unskilled workers may decrease but that of skilled workers may increase owing to the restriction of foreign unskilled workers.
\end{abstract}

\section{Introduction}

The word "international migration" usually refers to labor inflows for higher developed countries (HDCs) such as Germany, Japan, and the United States. For lower developed countries (LDCs) such as Bangladesh, Cambodia, and most African countries, migration implies an outflow of labor. Most of the economic literature has focused on mutual relationships between the source and host countries and studied the effects of international migration on the economies of those countries. However, globalization in the more recent past has resulted in several new types of international migration. In observing the recent expansion of multilateral economic integration between countries at various phases of development, we recognize that several medium developed countries (MDCs) are playing a new role in the international labor market. These MDCs export labor to HDCs and, simultaneously, import labor from LDCs. In other words, these countries are coincidentally host as well as source countries and are at the midstream of international labor flows.

For example, the Romanian economy is placed almost precisely between those of HDCs such as Belgium, Germany, and the Netherlands and LDCs such as Albania, Moldova, and Ukraine ${ }^{1}$. Until 2007, Romania was excluded from a large economic bloc of developed countries, the European Union (EU), and thus, free mobility of goods and factors was not permitted. Hence before 2007, despite of relatively lower wage rates and limited job opportunities, high levels of migration from Romania to the EU did not occur. When the EU expanded in 2007, Romania was permitted to join the bloc and its local economy was successfully integrated into the EU. Romania started to enjoy rapid economic progress by attracting foreign investment and exporting workers to Germany, Italy, and Spain. Remittances enable those left behind to consume several types of modern manufactured goods produced only in the developed countries ${ }^{2}$. The labor market of the country has undergone drastic changes owing to FDI inflows, which create job opportunities, as well as the outflow of domestic workers. A key problem of this new economic wave is that quick changes have caused serious labor shortages in Romanian urban areas. To maintain its economic performance, Romania started to introduce Chinese workers from the spring of 2008, although their employment is limited to permitted firms. As of 2013, more than 3,000 Chinese workers are still employed in Romania, although several workers returned to China because of the 2008 global recession sparked by the collapse of Lehman Brothers.

Another example of an MDC in the international labor market is Thailand ${ }^{3}$. In 2009, about 150,000 relatively skilled 
Thai workers went to Taiwan and countries in the Middle East for job opportunities, while the country had a large inflow of lower skilled workers, amounting to 1300 thousand from Cambodia, Laos, and Myanmar. As seen by this substantial labor inflow, the government of Thailand has been ineffective in controlling the number of foreign workers. The government took the only option available and decided to approve numerous illegal workers by permitting their employment. Since 2006, immigration policy of Thailand has changed. Now immigrants are required to submit documents issued in their home countries that establish their nationalities. This new immigration policy still includes several points but Thailand has nevertheless started to introduce an optimally controlled immigration policy, which is regarded as the most important and urgent issue in the country ${ }^{4}$.

A similar case is seen in Mexico. More than 25 million workers migrate from Mexico to the United States, while southern Mexico is simultaneously faced with immigration from Central American countries such as Guatemala. Those immigrants' final destinations are often the United States or Canada. Thus, to them, Mexico serves as a transit country until they find good opportunities elsewhere ${ }^{5}$.

Numerous theoretical studies on the economic effects of international migration employ two-country models or small-country models. However, no studies consider the economies of midstream countries that face both outflows and inflows of workers and need to introduce immigration and emigration policies simultaneously.

One pioneering study is that by MacDougall [1], who studies the gains from free factor movement by means of a simple two-factor, two-country, one-good model. He finds that, even though free factor movement might be best for the global economy, most countries adopt several types of policies restricting such movement to maximize domestic welfare. The choice between an optimally controlled labor import policy and a capital export policy is investigated by Ramaswami [2] in his seminal study that is an extension of MacDougall [1]; several studies follow as extensions to Ramaswami $[2]^{6}$.

With regard to immigration policies, Djajic [3] studies the economic effects of qualitative restriction policies on legal immigration, while Kondoh [4] studies illegal immigrants, in which illegal workers optimally choose not to legalize their employment status despite having the option to do so in due course, which is a minor extension of Djajic's study. Applying a three-country model-two developed countries and one developing country-Coniglio and Kondoh [5] studied the effects of economic integration between countries with heterogeneous immigration policies-one country adopts a qualitative restriction policy while another adopts a quantitative restriction policy. However, no studies consider the economies of midstream countries that face both outflows and inflows of workers and need to introduce immigration and emigration policies simultaneously.

As the case of Thailand demonstrates, the most important issues for such midstream countries affected by international migration are to control brain drain caused by outflow of skilled workers as well as the immigration of LDCs' unskilled workers. Well-controlled unskilled workers' immigration may result in positive effects on the economic welfare of the midstream country even though it may cause negative effects on the wage gap between domestic skilled and unskilled workers. This study adopts a two-factor, three-country model with one good, following MacDougall [1]. As only one good is produced in each country, there is no trade between countries. The two factors are skilled and unskilled labor and their endowments are flexibly changeable by skill formation. The three countries comprise an HDC, LDC, and MDC. Using this framework, we investigate the economic effects of immigration restriction policies on the number of domestic skilled/unskilled workers, the number of foreign unskilled workers, and economic welfare (as measured by national income). We compare two different cases: free immigration (or out of control immigration) and optimally controlled unskilled workers' immigration.

The main findings are as follows. Compared with the case where free immigration is allowed, if the MDC adopts an optimally controlled immigration policy and imposes income tax on immigrants to maximize national income, skill formation is negatively affected and the number of domestic unskilled workers increases. Moreover, under certain conditions, we can assert the counter-intuitive possibility that the wage rates of domestic unskilled workers may decrease but that of skilled workers may increase owing to the restriction of foreign unskilled workers. This result occurs in case that the decreasing number of domestic skilled workers caused by skill formation effect dominates the decreasing number of unskilled workers which is the sum of decreasing unskilled immigrants and increasing domestic unskilled workers.

The remainder of this paper is organized as follows. In Section 2, we present the model. Comparative static analyses are performed in Section 3, while Section 4 presents concluding remarks.

\section{A Simple Three-Country Model of International Migration}

2.1. Production and Wage Rates. We assume the manufacturing industry of country $B$, a medium developed country (MDC), is labor intensive. We assume a relatively scarce role for capital in the production of this country, with capital being completely substituted by skilled workers. Therefore, similar to, for example, Chao and Yu [6], the primary factors of production in country $B$ are two types of labor: skilled workers $(S)$ and unskilled workers $(U)$. For full employment, the following condition needs to be satisfied:

$$
L_{B}^{U}+L_{B}^{S}=\bar{L}_{B}
$$

where $\bar{L}_{B}$ denotes fixed labor endowment in country $B$. However, note that the distribution of the two types of workers is determined endogenously by solving the individual's lifelong income maximization problem; thus, the two factors are substitutable in production, as ordinarily in the case of 
capital and labor. To simplify our analysis, let us specify the production function as follows:

$$
X_{B}=L_{B}^{U} L_{B}^{S}-\frac{a}{2}\left(L_{B}^{U}\right)^{2}-\frac{b}{2}\left(L_{B}^{S}\right)^{2}
$$

where $L_{B}^{U}$ and $L_{B}^{S}$ are the number of domestic unskilled and skilled workers, respectively, in country $B^{7}$. We assume that the following conditions are satisfied before and after international migration: $0<a<L_{B}^{S} / L_{B}^{U}$ and $0<b<$ $L_{B}^{U} / L_{B}^{S}$, which are necessary to obtain positive marginal products of labor in both sectors. Now we have the following properties under perfect competition in both factor markets: $\partial X_{B} / \partial L_{B}^{S}=L_{B}^{U}-b L_{B}^{S}=w_{B}^{S}>0, \partial X_{B} / \partial L_{B}^{U}=L_{B}^{S}-a L_{B}^{U}=w_{B}^{U}>$ $0, \partial^{2} X_{B} / \partial\left(L_{B}^{S}\right)^{2}=-b<0, \partial^{2} X_{B} / \partial\left(L_{B}^{U}\right)^{2}=-a<0$, and $\partial^{2} X_{B} / \partial L_{B}^{S} \partial L_{B}^{U}=1>0$, where $w_{B}^{S}$ and $w_{B}^{U}$ denote the wage rates of skilled and unskilled workers, respectively, in country $B$, while the price of the products is taken as a numeraire. Without loss of generality, we assume

$$
L_{B}^{U}>\frac{1+b}{1+a} L_{B}^{S}
$$

which implies $w_{B}^{S}>w_{B}^{U}$ in equilibrium.

In contrast, we assume that in the highly developed country (HDC), country $A$, the manufacturing industry is capital intensive, with the primary factors of this country being capital and skilled workers. Here, we emphasize a difference from the case of the MDC, in the existence of fixed legal minimum wage rates for workers employed in country $A: \bar{w}_{A}^{S}\left(>w_{B}^{S}\right)^{8}$. Those workers are treated equally to domestic workers in country $A$.

Finally, in a lower developed country (LDC), country $C$, the main industry is agriculture. The primary factors of production are land and labor, while all workers are unskilled. Similar to the case of country $B$, we specify the production function as follows:

$$
X_{C}=T_{C} L_{C}^{U}-\frac{a^{\prime}}{2}\left(L_{C}^{U}\right)^{2}-\frac{b^{\prime}}{2} T_{C}^{2},
$$

where $L_{C}^{U}$ and $T_{C}$ denote the number of unskilled workers and fixed endowment of land, respectively, in country $C$. We also assume perfect competition and full employment in this country. Under the assumption of a sufficiently large fixed labor endowment, $\bar{L}_{C}^{U}$, we can assert $w_{B}^{U}>w_{C}^{U}$ in autarky, where $w_{C}^{U}$ is the competitive wage rate of country $C$.

2.2. Brain-Drain Migration from Country B to A. Assume that each individual in country $B$ is identical and survives for the period $T$. The wage rate of an unskilled worker in country $B, w_{B}^{U}$, is low and, for simplicity, we assume that income is spent entirely on consumption and not saved for sustaining future consumption. In other words, the desired minimum level of consumption is, by assumption, lower or equal to $w_{B}^{U}$. On the other hand, the income of a skilled worker is higher than that of an unskilled worker; moreover, some skilled workers have the opportunity to migrate to country
$A$ legally for employment at a fixed higher wage rate. Thus, each individual in country $B$ intends to be a skilled worker at the beginning, but this requires spending for the education cost of a specific human capital, $\mu$. At age $\tau(0<\tau<T)$, the individual finishes accumulating the required level of skills and will then be employed as a skilled worker. The following condition should be satisfied in equilibrium in which nobody has an incentive to invest in human capital in order to be a skilled worker anymore:

$$
\left[p\left(\bar{w}_{A}^{S}-\gamma_{1}\right)+(1-p) w_{B}^{S}-w_{B}^{U}\right][T-\tau]-\mu=0,
$$

where $\gamma_{1}$ is the fixed trip cost from $B$ to $A$ and $p$ is the rate of country $B$ 's skilled workers being employed in country $A$, which satisfies the following relationship, $p=L_{A B}^{S} / L_{B}^{S} 9$. For simplicity, we assume no intertemporal discount factor.

2.3. Unskilled Workers' Migration from Country $C$ to $B$. Assume that country $B$ confronts the inflow of unskilled foreign workers from country $C$, the neighboring LDC. Following the case of Thailand, we assume free immigration. We call this benchmark case as Case 1 . After several immigration challenges faced by the government, country $B$ succeeds in controlling the optimal number of immigrants to maximize its national income. We call this Case $2^{10}$.

First, we consider Case 1. As there are no restrictions on migration, workers migrate from country $C$ to country $B$ until there is no income gap between the two countries. Then, the number of immigrants, $L_{B C}^{U}$, should satisfy the following condition:

$$
(1-p) L_{B}^{S}-a\left(L_{B}^{U}+L_{B C}^{U}\right)=T_{C}-a^{\prime}\left(\bar{L}_{C}^{U}-L_{B C}^{U}\right) .
$$

In Figure 1, which is frequently applied to explain MacDougall's model, $O$ and $O^{*}$ denote the origin point of country $B$ and country $C$, respectively. The vertical line shows the value of marginal products of labor in countries $B$ and $C$, while the horizontal line shows labor inputs. The distances $O R$ and $R O^{*}$ denote $L_{B}^{U}$ and $\bar{L}_{C}^{U}$, respectively; therefore, the distance between $O$ and $O^{*}$ equals the total endowment of unskilled workers of both countries.

In Case 1 , because of the arbitrage condition between countries, the number of immigrants from $C$ to $B$ is equal to the distance $R N$. Then, considering that the national income (NI) of country $B$ is equal to GDP minus immigrants' income, NI can be expressed by the area OGEDR:

$$
\mathrm{NI}_{B}^{1}=\frac{a}{2}\left(L_{B}^{U}+L_{B C}^{U}\right)^{2}+L_{B}^{U}\left[(1-p) L_{B}^{S}-a\left(L_{B}^{U}+L_{B C}^{U}\right)\right],
$$

and by applying (1) and (6), $\mathrm{NI}_{B}^{1}$ can be expressed as a function of $L_{B}^{S} 11$.

Second, in Case 2, immigrants confront restriction policies imposed by the government of the host country. We assume that individuals are risk-neutral when they decide to migrate illegally. Considering that developed countries usually accept the entry of sightseeing travelers and a considerable number of illegal workers camouflage themselves as such 


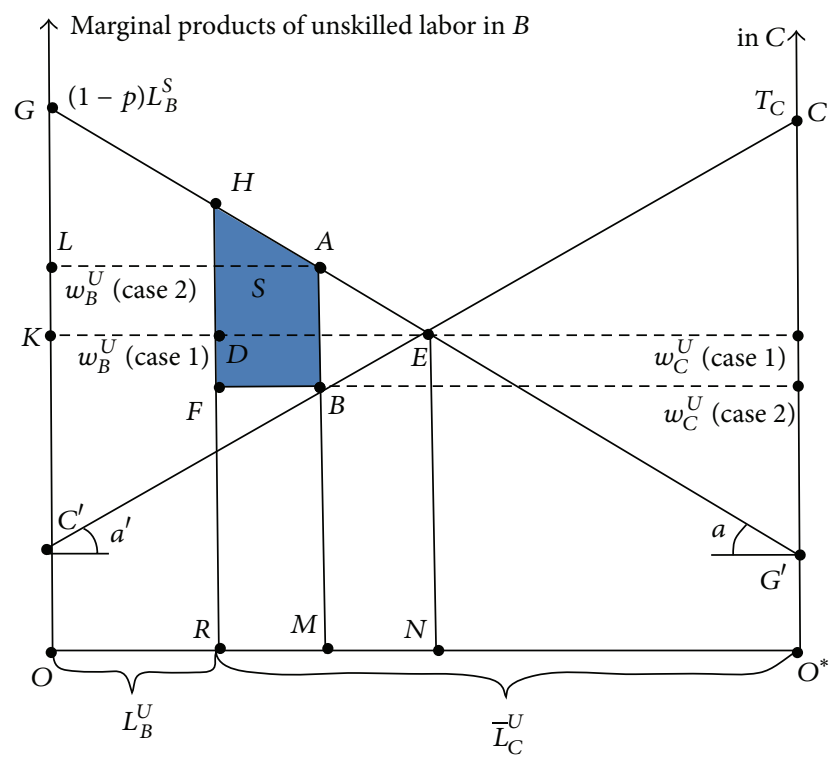

FIGURE 1: Unskilled workers' immigration to country $B$.

at borders, we assume no restriction of entry into country $B$. Illegal immigrants are assumed to be well-disguised as domestic workers but the government of $B$ makes a political effort to reduce illegal residency via internal enforcement policies. This means that an illegal worker, if detected while working, is fired and deported. We let $\rho \in[0,1]$ denote the probability of detection in every period and let $L_{B C}^{U}$ denote the number of succeeded illegal immigrants. The probability of detection is known to potential illegal migrants and is negatively related to the total number of aggregate illegal immigrants (both succeeded and failed) from country $C$, $L_{B C}^{U} /(1-\rho)$. As the government's efforts to reduce illegal immigrants remain constant, the probability of detection for an illegal worker is not only a decreasing function of the total number of aggregate illegal workers but also a decreasing function of succeeded illegal immigrants ${ }^{12}$. Let the penalty cost that an illegal immigrant should pay in the case of detection, $\theta$, be constant. In equilibrium, in each period, the expected income of illegal migrants should be equal to that of those left behind:

$$
\left(1-\rho\left(L_{B C}^{U}\right)\right) w_{B}^{U}+\rho\left(L_{B C}^{U}\right)\left(w_{C}-\theta\right)-\gamma_{2}=w_{C}
$$

where $\gamma_{2}$ denotes the fixed trip cost from $C$ to $B$ and we assume, for simplicity, that the travel cost of migration (and return) is null ${ }^{13}$.

We consider a situation in which, given the skills accumulation of domestic workers, the number of illegal workers is determined endogenously by the government of country $B$ in order to maximize the economic welfare of its native population, the sum of domestic skilled workers' income, unskilled workers' income, and government income ${ }^{14}$. Government income consists of penalty charges paid by illegal workers who are detected. In Figure 1, this implies the optimal choice of $R M$, the number of illegal workers, to maximize the area $O G A B F R$. This area can be expressed numerically as

$$
\begin{aligned}
\mathrm{NI}_{B}^{2}= & -\left(a^{\prime}+\frac{a}{2}\right)\left(L_{B C}^{U}\right)^{2} \\
& +L_{B C}^{U}\left[(1-p) L_{B}^{S}-a\left(L_{B}-L_{B}^{S}\right)-T_{C}+a^{\prime} L_{C}^{U}\right],
\end{aligned}
$$

and the first order condition of the national income maximizing problem is

$$
\begin{aligned}
\frac{\partial \mathrm{NI}_{B}}{\partial L_{B C}^{U}}= & -\left(2 a^{\prime}+a\right) L_{B C}^{U} \\
& +\left[(1-p) L_{B}^{S}-a\left(L_{B}-L_{B}^{S}\right)-T_{C}+a^{\prime} L_{C}^{U}\right]=0 .
\end{aligned}
$$

Making use of $w_{B}^{S}=w_{B}^{S}\left(L_{B}^{S}\right), w_{B}^{U}=w_{B}^{U}\left(L_{B}^{S}, L_{B C}^{U}\right)$, in Case 1 , two endogenous variables $L_{B}^{S}$ and $L_{B C}^{U}$ are determined from the two equations (5) and (6), while in Case 2, these two variables are determined from (5) and (10), whilst the optimal level of $\theta$ is determined from (8). This completes the setup of the model.

\section{Multilateral Economic Integration}

First, we consider Case 1. By differentiating (5) and (6) and considering that $L_{B}^{U}+L_{B}^{S}=L_{B}$ and that therefore $d L_{B}^{U}$ also implies $-d L_{B}^{S}$, we derive the following equation:

$$
\begin{aligned}
& {\left[\begin{array}{cc}
\Psi & \Phi \\
1-p+a & -\left(a+a^{\prime}\right)
\end{array}\right]\left[\begin{array}{c}
d L_{B}^{S} \\
d L_{B C}^{U}
\end{array}\right]} \\
& \quad=\left[\begin{array}{l}
1 \\
0
\end{array}\right] d \mu+\left[\begin{array}{c}
-p \\
0
\end{array}\right] d \bar{w}_{A}+\left[\begin{array}{c}
-W \\
0
\end{array}\right] d \tau,
\end{aligned}
$$

where $\lambda_{i} \equiv\left(\bar{w}_{A}^{S}-w_{B}^{S}\right)\left(d p / d L_{B}^{S}\right)=\left(\bar{w}_{A}^{S}-w_{B}^{S}\right) L_{A B}^{S}\left(L_{B}^{S}\right)^{-2}>0$, $i=1,2$,

$$
\begin{gathered}
\Psi=\left\{(1-p) \frac{\partial w_{B}^{S}}{\partial L_{B}^{S}}-\frac{\partial w_{B}^{U}}{\partial L_{B}^{S}}+\left(\bar{w}_{A}^{S}-w_{B}^{S}\right) \frac{d p}{d L_{B}^{S}}\right\}(T-\tau) \\
=\{-(1-p)(1+b)-(1+a) \\
\left.-\left(\bar{w}_{A}^{S}-w_{B}^{S}\right) L_{A B}^{S}\left(L_{B}^{S}\right)^{-2}\right\}(T-\tau)<0, \\
\Phi=\left\{-\frac{\partial w_{B}^{U}}{\partial L_{B C}^{U}}\right\}(T-\tau)=a(T-\tau)>0, \\
W=p \bar{w}_{A}^{S}+(1-p) w_{B}^{S}-w_{B}^{U} .
\end{gathered}
$$

The determinant of the matrix of the LHS of (11) is

$$
\begin{gathered}
\Delta_{1}=(T-\tau)\left\{\left(a+a^{\prime}\right)\left[(1-p)(1+b)+(1+a)+\lambda_{1}\right]\right. \\
-a(1-p+a)\}>0 .
\end{gathered}
$$




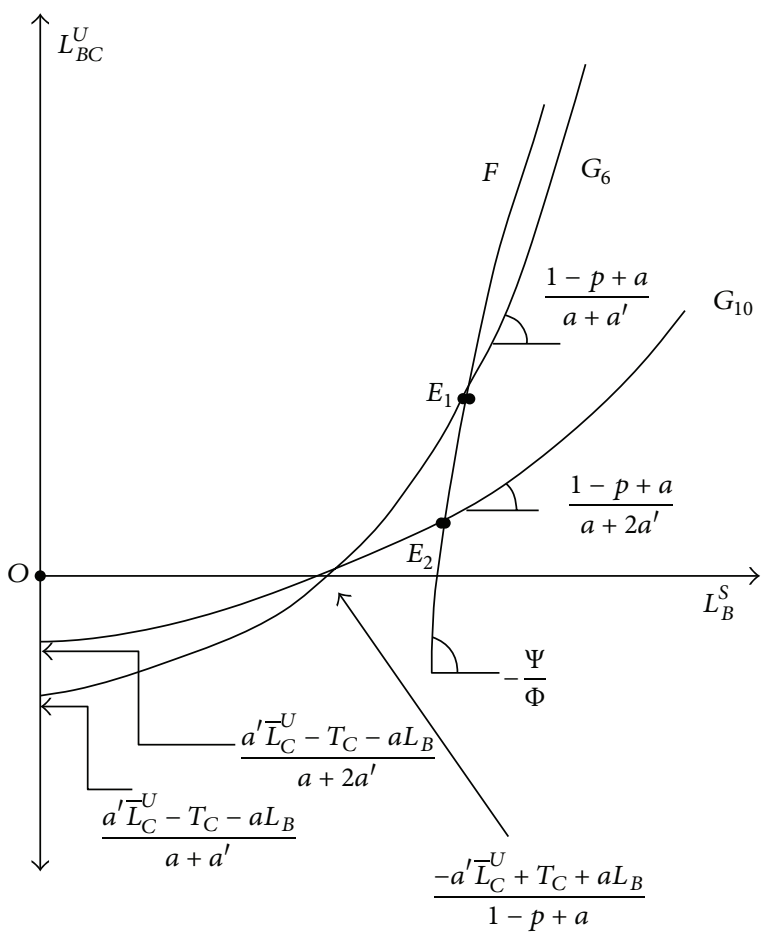

Figure 2: The determination of $L_{B}^{S}$ and $L_{B C}^{U}$.

Similarly, for Case 2, from (5) and (10) we obtain

$$
\begin{aligned}
& {\left[\begin{array}{cc}
\Psi & \Phi \\
1-p+a & -\left(a+2 a^{\prime}\right)
\end{array}\right]\left[\begin{array}{c}
d L_{B}^{S} \\
d L_{B C}^{U}
\end{array}\right]} \\
& \quad=\left[\begin{array}{l}
1 \\
0
\end{array}\right] d \mu+\left[\begin{array}{c}
-p \\
0
\end{array}\right] d \bar{w}_{A}^{S}+\left[\begin{array}{c}
-W \\
0
\end{array}\right] d \tau .
\end{aligned}
$$

The determinant of the LHS of (14) can be expressed as

$$
\begin{aligned}
\Delta_{2}=(T-\tau)\left\{\left(a+2 a^{\prime}\right)[\right. & (1-p)(1+b) \\
& \left.\left.+(1+a)+\lambda_{2}\right]-a(1-p+a)\right\}
\end{aligned}
$$

$>0$.

Under given parameters $\bar{w}_{A}^{S}, \mu, \tau$, and $\gamma_{1}$, we can numerically express Figure 2 that shows the schedules in $\left(L_{B}^{S}, L_{B C}^{U}\right)$ dimension $^{15}$. Considering that $d p / d L_{B}^{S}=-L_{A B}^{S}\left(L_{B}^{S}\right)^{-2}<0$, we can ascertain that line $G_{6}$ corresponds to (6) in Case 1 and that line $G_{10}$ corresponds to (10) in Case 2, respectively, as convex functions of $L_{B}^{S}$. In addition, considering that $d \lambda / d L_{B}^{S}=-L_{A B}^{S}\left(L_{B}^{S}\right)^{-2}\left\{2\left(\bar{w}_{A}^{S}-w_{B}^{S}\right)\left(L_{B}^{S}\right)^{-1}+(1+b)\right\}<0$, we can ascertain that line $F$ corresponds to (5) and, in Case 1 as well as Case 2, is a concave function of $d L_{B}^{S}$. Thus, in equilibrium, in Case 2, we can conclude smaller $L_{B}^{S}$ and $L_{B C}^{U}$ with larger $L_{B}^{U}$. That is, in the case where country $B$ enacts an immigration restriction policy, there will be less domestic skilled labor, less unskilled labor from country $C$, and more domestic unskilled labor. Again, as both equilibrium points in Figure 2, $E_{1}$ and $E_{2}$, are on line $F$, the slope of which is $d L_{B C}^{U} / d L_{B}^{S}=\left((1-p)(1+b)+(1+a)+\lambda_{i}\right) / a>1$ and $d\left\{(1-p) L_{B}^{S}\right\} / d L_{B}^{S}=1$, we can conclude that both the number of skilled workers and unskilled workers in country $B$ are smaller in Case 2 than that in Case 1. This implies that an immigration restriction policy adopted by country $B$ will have negative effects on skill formation in that country.

Furthermore, if $a<L_{B}^{S} / L_{B}^{U}<1$, which implies that the number of domestic skilled workers is less than domestic unskilled workers, because of $d L_{B C}^{U} / d L_{B}^{S}>2$ which implies $d\left[L_{B C}^{U}+L_{B}^{U}\right] / d L_{B}^{S}>1$, we can conclude that the marginal product of skilled workers-equal to the wage rate of those workers in country $B$-is smaller in Case 2 than that in Case 1. By contrast, the wage rate of unskilled workers in country $B$ is larger in Case 2 than that of Case 1. Thus, under an optimally controlled restriction policy, the wage rate of skilled workers is lower than that under free migration.

On the other hand, if condition $d L_{B C}^{U} / d L_{B}^{S}<2$ which implies $d\left[L_{B C}^{U}+L_{B}^{U}\right] / d L_{B}^{S}<1$ is satisfied, as we have $d w_{B}^{S}=$ $\left(d L_{B}^{U}+d L_{B C}^{U}\right)-b d L_{B}^{S}=\left[d\left(L_{B}^{U}+L_{B C}^{U}\right) / d L_{B}^{S}-b\right] d L_{B}^{S}$ and $d w_{B}^{U}=$ $d L_{B}^{S}-a\left(d L_{B}^{U}+d L_{B C}^{U}\right)=\left[1-a\left(d\left(L_{B}^{U}+L_{B C}^{U}\right) / d L_{B}^{S}\right)\right] d L_{B}^{S}$ from (2), depending on the magnitude of parameters, the wage rates of skilled workers might be larger than those under free migration while those of unskilled workers might be smaller under an optimally controlled restriction policy ${ }^{16}$.

This counter-intuitive result, which implies that a restriction of the inflow of unskilled foreign workers results in wage reduction for domestic unskilled workers, could be caused by a change in domestic workers' optimal choices in skills formation. In any case, by restriction, the number of illegal unskilled workers decrease and that dominates both the numbers of increasing domestic unskilled workers and decreasing domestic skilled workers. Thus in total, unskilled workers in country $B$ should decrease. But in case that the dominated skill formation effect is sufficiently not so small, decreased number of skilled workers could be larger than that of unskilled workers which is the sum of decreased foreign immigrants and increased domestic unskilled workers. This concludes that unskilled/skilled ratio of workers in country $B$ could increase after restriction ${ }^{17}$. Figure 3 shows this case. Finally, we find that as country $B$ optimally controls the number of immigrants-free immigration remains an optionby imposing taxes, its economic welfare is larger in Case 2; national income of this case equals the area $O^{\prime} G^{\prime} A^{\prime} B^{\prime} F^{\prime} R$ more than that in Case 1, area OGEDR in Figure 3.

With regard to comparative statics analysis, we obtain $\Delta_{i}\left(d L_{B}^{S} / d \mu\right)<0, \Delta_{i}\left(d L_{B C}^{U} / d \mu\right)<0, \Delta_{i}\left(d L_{B}^{S} / d \bar{w}_{A}^{S}\right)>0$, $\Delta_{i}\left(d L_{B C}^{U} / d \bar{w}_{A}^{S}\right)>0, \Delta_{i}\left(d L_{B}^{S} / d \gamma_{1}\right)<0, \Delta_{i}\left(d L_{B C}^{U} / d \gamma_{1}\right)<$ $0, \Delta_{i}\left(d L_{B}^{S} / d \tau\right)>0$, and $\Delta_{i}\left(d L_{B C}^{U} / d \tau\right)>0$, in line with our ordinary intuition. Although the signs of changes in endogenous variables caused by increases in parameters are identical in both cases, the magnitudes of the effects should differ depending on the parameters.

\section{Concluding Remarks}

This study investigated the economy of a small country that exports skilled labor to higher developed countries and 


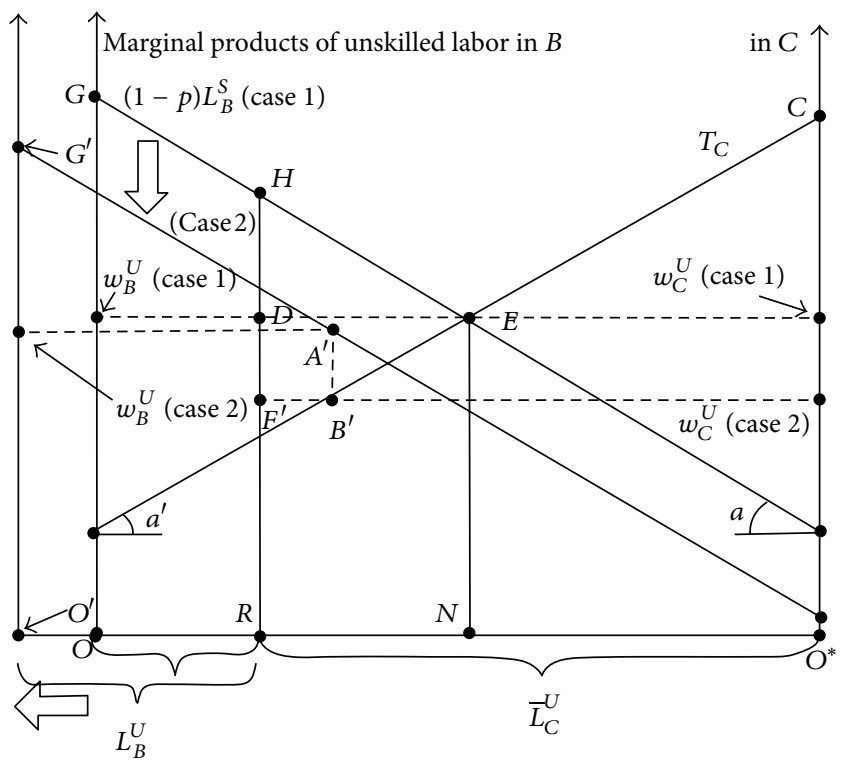

FIGURE 3: The counter-intuitive case considering skill formation.

simultaneously imports unskilled labor from lower developed countries. Analysis results revealed that compared with the case of free immigration, if this country adopts an optimally controlled immigration policy by imposing income tax on immigrants to maximize national income, skill formation is negatively affected and the number of domestic unskilled workers increases. Moreover, under certain conditions, we can assert the counter-intuitive possibility that the wage rate of domestic unskilled workers may decrease but that of skilled workers may increase owing to the restriction of foreign unskilled workers. Therefore, the policy implication of this study is that, even though it yields lower national income, free immigration of unskilled workers might be better if the host country stresses skill formation of domestic workers.

This study is based on a simple model that excludes international trade, FDI, and definite dynamic skill formation systems, in line with Djajic [3]. We also consider other types of immigration restriction policies such as quotas or permission for short period stays. Furthermore, we assume the source country to be somewhat passive, and we did not consider any interactions with country $C$. Incorporating these issues could change our simple results; this remains a topic for future studies.

\section{Appendix}

The detailed calculations of the comparative statics are as follows:

$$
\begin{aligned}
\Delta_{1} \frac{d L_{B}^{S}}{d \mu} & =\left|\begin{array}{cc}
1 & \Phi \\
0 & -a-a^{\prime}
\end{array}\right|=-\left(a+a^{\prime}\right)<0, \\
\Delta_{1} \frac{d L_{B C}^{U}}{d \mu} & =\left|\begin{array}{cr}
\Psi & 1 \\
1-p+a & 0
\end{array}\right|=-(1-p+a)<0,
\end{aligned}
$$

$$
\begin{aligned}
& \Delta_{1} \frac{d L_{B}^{S}}{d \bar{w}_{A}^{S}}=-\Delta_{1} \frac{d L_{B}^{S}}{d \gamma_{1}} \\
& =\left|\begin{array}{cc}
-p & \Phi \\
0 & -a-a^{\prime}
\end{array}\right|=p\left(a+a^{\prime}\right)>0, \\
& \Delta_{1} \frac{d L_{B C}^{U}}{d \bar{w}_{A}^{S}}=-\Delta_{1} \frac{d L_{B C}^{U}}{d \gamma_{1}} \\
& =\left|\begin{array}{cc}
\Psi & -p \\
1-p+a & 0
\end{array}\right|=p(1-p+a)>0, \\
& \Delta_{1} \frac{d L_{B}^{S}}{d \tau}=\left|\begin{array}{cc}
-W & \Phi \\
0 & -a-a^{\prime}
\end{array}\right|=W\left(a+a^{\prime}\right)>0, \\
& \Delta_{1} \frac{d L_{B C}^{U}}{d \tau}=\left|\begin{array}{cc}
\Psi & -W \\
1-p+a & 0
\end{array}\right|=W(1-p+a)>0, \\
& \Delta_{2} \frac{d L_{B}^{S}}{d \mu}=\left|\begin{array}{cc}
1 & \Phi \\
0 & -a-2 a^{\prime}
\end{array}\right|=-\left(a+2 a^{\prime}\right)<0, \\
& \Delta_{2} \frac{d L_{B C}^{U}}{d \mu}=\left|\begin{array}{cc}
\Psi & 1 \\
1-p+a & 0
\end{array}\right|=-(1-p+a)<0, \\
& \Delta_{2} \frac{d L_{B}^{S}}{d \bar{w}_{A}^{S}}=-\Delta_{2} \frac{d L_{B}^{S}}{d \gamma_{1}}=\left|\begin{array}{cc}
-p & \Phi \\
0 & -a-2 a^{\prime}
\end{array}\right| \\
& =p\left(a+2 a^{\prime}\right)>0, \\
& \Delta_{2} \frac{d L_{B C}^{U}}{d \bar{w}_{A}^{S}}=-\Delta_{2} \frac{d L_{B C}^{U}}{d \gamma_{1}}=\left|\begin{array}{cc}
\Psi & -p \\
1-p+a & 0
\end{array}\right| \\
& =p(1-p+a)>0 \text {, } \\
& \Delta_{2} \frac{d L_{B}^{S}}{d \tau}=\left|\begin{array}{cc}
-W & \Phi \\
0 & -a-2 a^{\prime}
\end{array}\right|=W\left(a+2 a^{\prime}\right)>0, \\
& \Delta_{2} \frac{d L_{B C}^{U}}{d \tau}=\left|\begin{array}{cc}
\Psi & -W \\
1-p+a & 0
\end{array}\right|=W(1-p+a)>0 .
\end{aligned}
$$

\section{Conflict of Interests}

The author declares that there is no conflict of interests regarding the publication of this paper.

\section{Acknowledgments}

The author would like to thank the anonymous referees for their helpful comments and suggestions. This study is financially supported by the Grant in Aid for Scientific Research of the Ministry of Education and Science (no. 25380340).

\section{Endnotes}

1. See Hamberger [7] for detailed information about the present situation of migration in Romania.

2. Following World Bank data, remittances sent home by Romanians abroad, flat at USD 3.6 bln in 2013.

3. See Fujita et.al. [8] and Yamada [9] for detailed information of labor inflow and outflow in Thailand. 
4. Yamada [9] surveys the backgrounds and transition of immigration policies of Thailand. Fujita et al. [8] shed light on the actual working conditions and life of Myanmar migrants in Thailand, based on an intensive survey in Ranong in southern Thailand in 2009.

5. Considering the current situation about Mexican labor market, see Mariel [10], for example.

6. See Webb [11], Bhagwati [12], Calvo and Wellisz [13], Bhagwati and Srinivasan [14], Ruffin [15], Jones and Coelho [16], Jones et al. [17], Kuhn and Wooton [18], and Jones and Easton [19].

7. This specified production function has a quite convenient property that marginal product of labor is the linear decreasing function of labor input. This property is assumed by MacDougall [1] and most of the extension studies of this study adopt this assumption.

8. We assume the number of domestic skilled workers in country $A$ 's industrial sector is not sufficient and the marginal products of labor is higher than $\bar{w}_{A}^{S}$. Then for this sector, it is possible to enlarge total outputs and GDP by introducing some skilled workers from country $B$, $L_{A B}^{S}$, until the marginal products of labor are equal to $\bar{w}_{A}^{S}$. Thus legal migration of skilled workers is just to satisfy this shortage of workers. Another story is that immigration policy of country $A$ is quota and introduces fixed number of skilled workers from less developed countries. By the existence of social policy like livelihood protection system, we assume those migrants' expected income is not less than a crucial standard.

9. We introduce migration cost following Miyagiwa [20] and Contreras [21].

10. Djajic and Michael [22] and [23], respectively, studied the political interactions between the host and the source countries in the case of temporary workers and skilled workers' migration. In addition, Djajić et al. [24] studied similar subjects under the guest-worker system. To simplify our study, we consider only that the host country can introduce some restriction policies.

11. National income of country $B$ is just equal with the sum of domestic skilled workers' income (including both emigrants and those left behind) and domestic unskilled workers' income. As we focus on the nationality, regardless of the existing fraction of immigrants settled in their new homeland, immigrants' income is not included. In this study, as the number of emigrants and their wage rates are exogenously given, the government intends to maximize the sum of domestic unskilled workers' income: area $O K D R$ and remaining skilled workers' income: area GLA. Therefore, in reality area $O G E D R$ does not include emigrants' income; in this study we call this national income for convenience. We need to remark that GDP of country $B$ equals with area OGEN while unskilled immigrants' income is area $R D E N$.

12. In case that aggregate illegal immigrants $L_{B C}^{U} /(1-\rho)$ increase, then by definition, the probability of detection, $\rho$, decreases. That yields increasing $(1-\rho)$ and also increasing $L_{B C}^{U}=\left[L_{B C}^{U} /(1-\rho)\right](1-\rho)$. Thus we obtain negative relationship between $\rho$ and $L_{B C}^{U}$.

13. This model can be interpreted for legal migration where the government can maximize national income by imposing income tax on the wage of unskilled immigrants optimally.

14. Another scenario of country $B$ is optimal restriction of skilled emigration. Similar analysis can be done considering optimally controlled tax rate imposed on the income of emigrants.

15. From (6) and (10), we can conclude that there is no unskilled immigrants, $L_{B C}^{U}$, in case that $L_{B}^{S}=\widetilde{L}_{B}^{S} \equiv$ $\left(-a^{\prime} \bar{L}_{C}^{U}+T_{C}+a L_{B}\right) /(1-p+a)$. We consider certain value of parameters $\bar{w}_{A}^{S}, \mu, \tau$, and $\gamma_{1}$, which guarantees that the number of skilled domestic workers $L_{B}^{S}$ which satisfies (5) without unskilled immigrants is larger than $\widetilde{L}_{B}^{S}$. In this case, we obtain two equilibrium points, $E_{1}$ and $E_{2}$, of two respective cases.

16. If $p$ that is determined by (5) satisfies $p>1-$ $\left(a-\lambda_{i}\right) /(1+b)$, which implies that $d L_{B C}^{U} / d L_{B}^{S}<2$, $d\left(L_{B}^{U}+L_{B C}^{U}\right) / d L_{B}^{S}$ is positive in sign and it could be smaller than unit. As from (2), we have $d w_{B}^{S}=\left(d L_{B}^{U}+\right.$ $\left.d L_{B C}^{U}\right)-b d L_{B}^{S}=\left[d\left(L_{B}^{U}+L_{B C}^{U}\right) / d L_{B}^{S}-b\right] d L_{B}^{S}$ and $d w_{B}^{U}=$ $d L_{B}^{S}-a\left(d L_{B}^{U}+d L_{B C}^{U}\right)=\left[1-a\left(d\left(L_{B}^{U}+L_{B C}^{U}\right) / d L_{B}^{S}\right)\right] d L_{B}^{S}$, remembering that, after restriction $d L_{B}^{S}<0$, we can conclude that $d w_{B}^{S}>0$ if $d\left(L_{B}^{U}+L_{B C}^{U}\right) / d L_{B}^{S}<b$ and $d w_{B}^{U}<0$ if $d\left(L_{B}^{U}+L_{B C}^{U}\right) / d L_{B}^{S}<1 / a$.

17. Parameter $a$ denotes the marginal change of marginal products of unskilled labor in country $B$. And in reality, it seems not constant and not so large in midstream countries like Thailand. As we specify the production function as (2), parameter $a$ is independent of skill formation, the ratio of skilled/unskilled domestic labor. This simplified assumption is strong but it shows the existence of counter-intuitive result clearly which should be possible under more general production function case.

\section{References}

[1] G. D. A. MacDougall, "The benefits and costs of private investment from abroad: a theoretical approach," Economic Record, vol. 26, pp. 13-35, 1960.

[2] V. K. Ramaswami, "International factor movement and the national advantage," Economica, vol. 35, pp. 309-310, 1969.

[3] S. Djajic, "Skills and the pattern of migration: the role of qualitative and quantitative restrictions on international labor mobility," International Economic Review, vol. 30, no. 4, pp. 795809, 1989.

[4] K. Kondoh, "Legal migration and illegal migration: the effectiveness of qualitative and quantitative restriction policies," Journal of International Trade \& Economic Development, vol. 9, no. 3, pp. 223-241, 2000.

[5] N. D. Coniglio and K. Kondoh, "International integration with heterogeneous immigration policies," Mimeo, 2013. 
[6] C. Chao and E. S. H. Yu, "Immigration and welfare for the host economy with imperfect competition," Journal of Regional Science, vol. 42, no. 2, pp. 327-338, 2002.

[7] A. Hamberger, "Immigration and the integration of immigrants in Romania," Migrationonline.cz, 7 pages, 2010.

[8] K. Fujita, T. Endo, I. Okamoto, Y. Nakanishi, and M. Yamada, "Myanmar migrant labours in Ranong, Thailand," Discussion Paper Series 257, Institute of Developing Economies (IDE), JETRO, 2010.

[9] M. Yamada, "Current trends and issues of immigration policies in Thailand," in Higashi Asia ni okeru Hito no Idou no Houseido [ Law and Migration Policies in East Asia], M. Yamada, Ed., Chapter 4 of Interim Report FY 2011-2012 Research Topic 108, Institute of Developing Economies (IDE), JETRO, 2012, (Japanese).

[10] M. N. Mariel, "Mexican diaspola (lecture)," Institute of Global Studies, Doshisha University, 2011.

[11] R. L. Webb, "International factor movement and the national advantage, a Comment," Economica, vol. 37, pp. 81-84, 1970.

[12] J. Bhagwati, "International factor movements and national advantage," Indian Economic Review, vol. 14, no. 2, pp. 73-100, 1979.

[13] G. Calvo and S. Wellisz, "International factor mobility and national advantage," Journal of International Economics, vol. 14, no. 1-2, pp. 103-114, 1983.

[14] J. N. Bhagwati and T. N. Srinivasan, "On the choice between capital and labour mobility," Journal of International Economics, vol. 14, no. 3-4, pp. 209-221, 1983.

[15] R. J. Ruffin, "International factor movements," in Handbook of International Economics, R. W. Jones and and P. Kenen, Eds., vol. 1, North-Holland, Amsterdam, The Netherlands, 1984.

[16] R. W. Jones and I. Coelho, "International factor movements and Ramaswami argument," Economica, vol. 52, no. 207, pp. 359364, 1985.

[17] R. W. Jones, I. Coelho, and S. T. Easton, "The theory of international factor flows: the basic model," Journal of International Economics, vol. 20, no. 3-4, pp. 313-327, 1986.

[18] P. Kuhn and I. Wooton, "International factor movements in the presence of a fixed factor," Journal of International Economics, vol. 22, no. 1-2, pp. 123-140, 1987.

[19] R. W. Jones and S. T. Easton, "Perspectives on "buy-outs" and the Ramaswami effect," Journal of International Economics, vol. 27, no. 3-4, pp. 363-371, 1989.

[20] K. Miyagiwa, "Scale economies in education and the brain drain problem," International Economic Review, vol. 32, pp. 743-759, 1991.

[21] S. Contreras, "The influence of migration on human capital development," International Economic Journal, vol. 27, no. 3, pp. 365-384, 2013.

[22] S. Djajic and M. S. Michael, “Temporary migration policies and welfare of the host and source countries: a game-theoretic approach," CESifo Working Paper Series 2811, 2009.

[23] S. Djajić and M. S. Michael, "Guest worker programs: a theoretical analysis of welfare of the host and source countries," Journal of International Trade and Economic Development, vol. 22, no. 3, pp. 454-475, 2013.

[24] S. Djajić, M. S. Michael, and A. Vinogradova, "Migration of skilled workers: policy interaction between host and source countries," Journal of Public Economics, vol. 96, no. 11-12, pp. 1015-1024, 2012. 

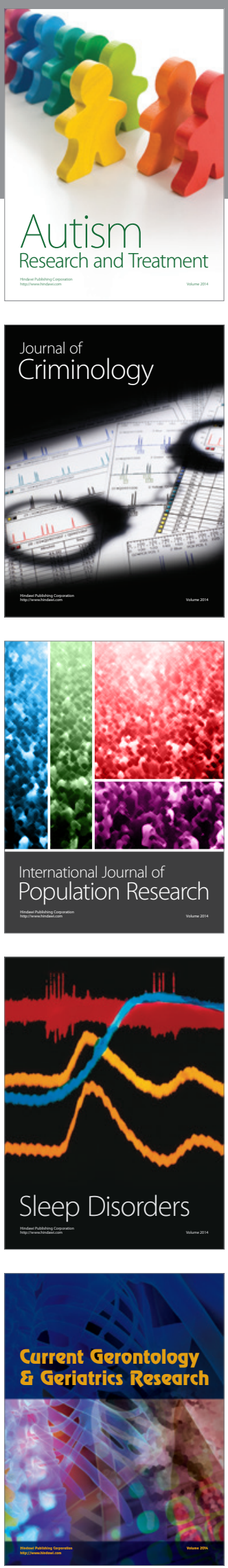
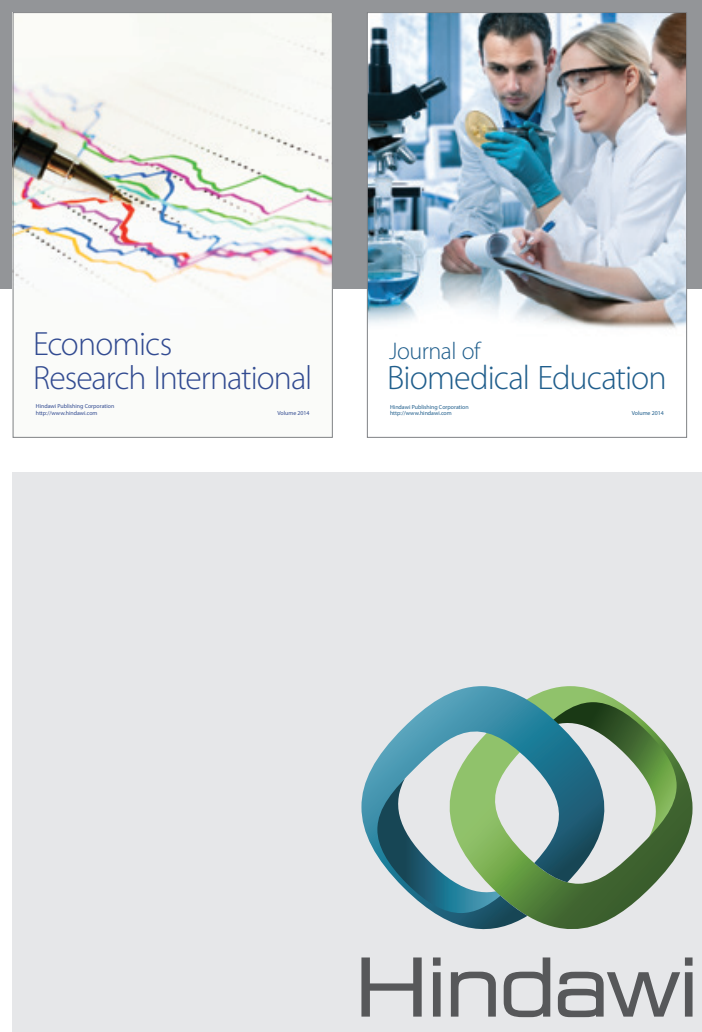

Submit your manuscripts at

http://www.hindawi.com
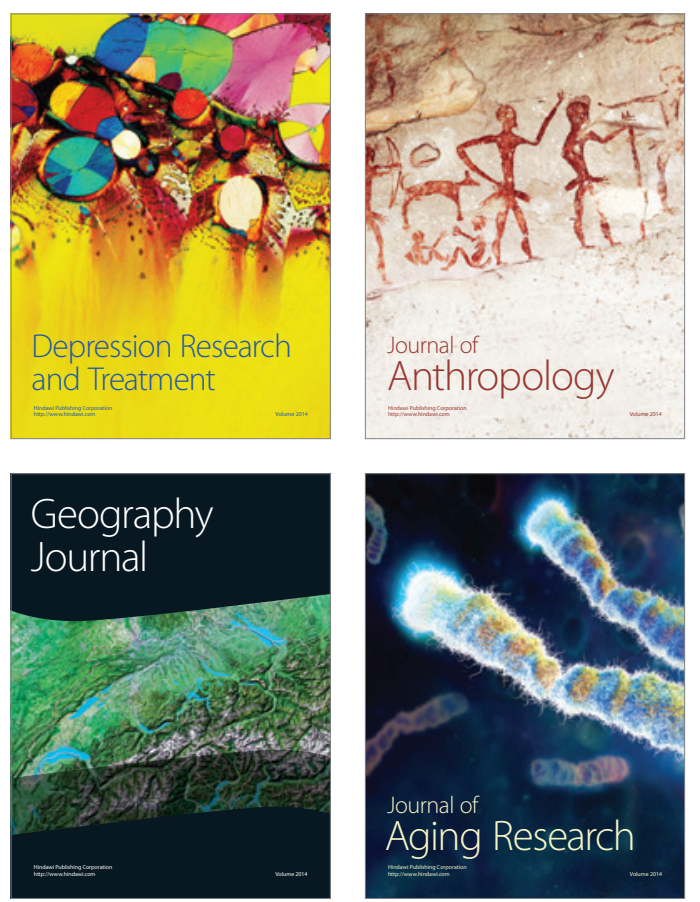
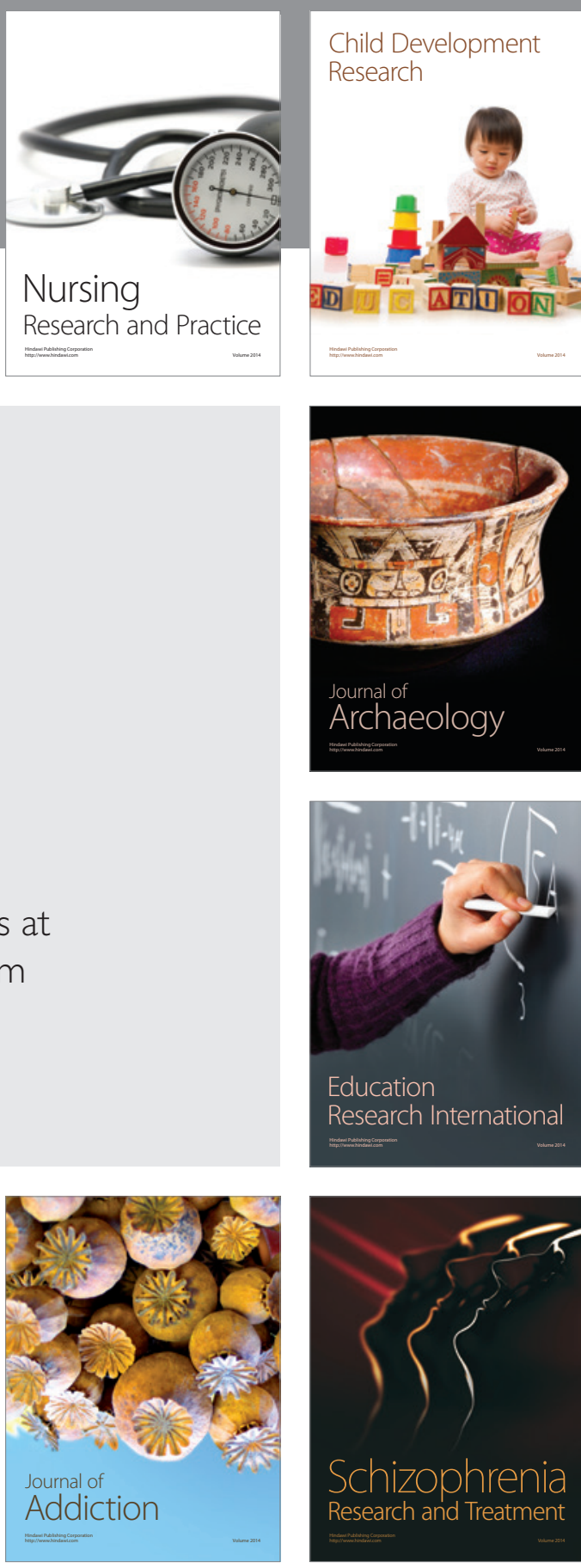

(D)
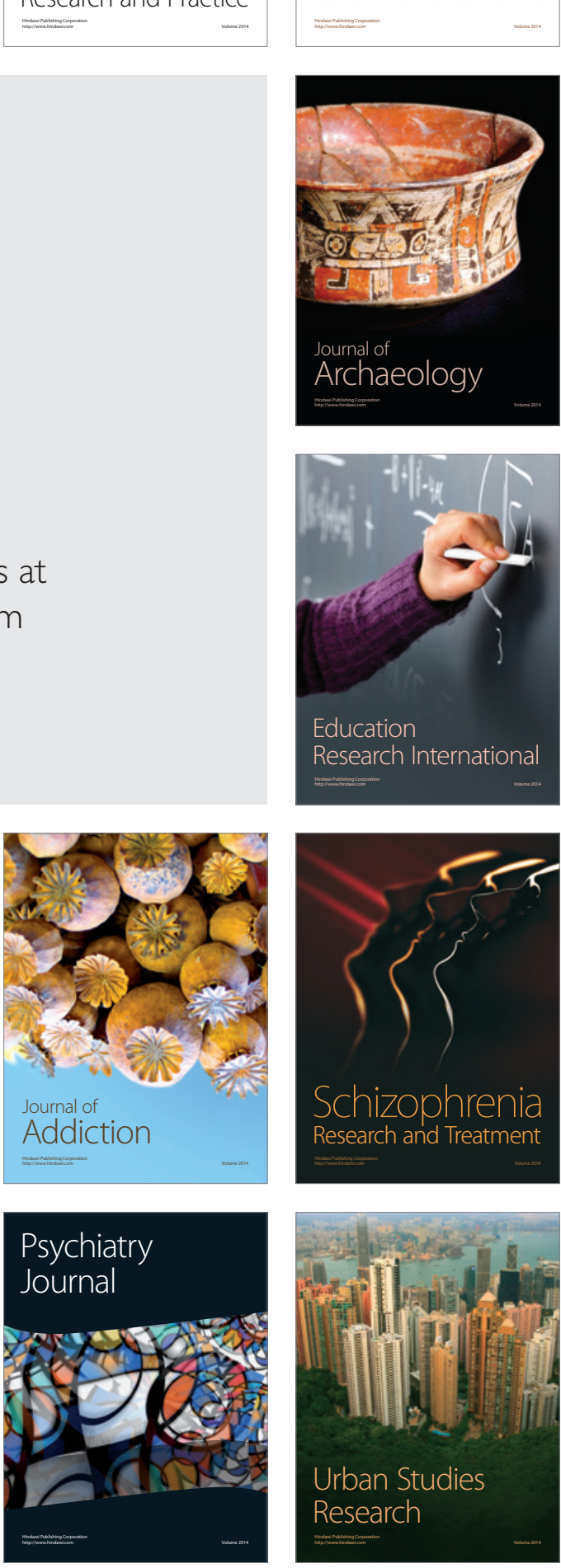